\title{
Various pathways of zoledronic acid against osteoclasts and bone cancer metastasis: a brief review
}

\author{
Lianwei Wang ${ }^{1 \dagger}$, Dengyang Fang ${ }^{1 \dagger}$, Jinming $\mathrm{Xu}^{1}$ and Runlan Luo ${ }^{2^{*}}$
}

\begin{abstract}
Zoledronic acid (ZA) is one of the most important and effective class of anti-resorptive drug available among bisphosphonate (BP), which could effectively reduce the risk of skeletal-related events, and lead to a treatment paradigm for patients with skeletal involvement from advanced cancers. However, the exact molecular mechanisms of its anticancer effects have only recently been identified. In this review, we elaborate the detail mechanisms of ZA through inhibiting osteoclasts and cancer cells, which include the inhibition of differentiation of osteoclasts via suppressing receptor activator of nuclear factor $\mathrm{KB}$ ligand (RANKL)/receptor activator of nuclear factor $\mathrm{KB}$ (RANK) pathway, non-canonical Wnt/Ca2+/calmodulin dependent protein kinase II (CaMKII) pathway, and preventing of macrophage differentiation into osteoclasts, in addition, induction of apoptosis of osteoclasts through inhibiting farnesyl pyrophosphate synthase (FPPS)-mediated mevalonate pathway, and activation of reactive oxygen species (ROS)-induced pathway. Furthermore, ZA also inhibits cancer cells proliferation, viability, motility, invasion and angiogenesis; induces cancer cell apoptosis; reverts chemoresistance and stimulates immune response; and acts in synergy with other anti-cancer drugs. In addition, some new ways for delivering ZA against cancer is introduced. We hope this review will provide more information in support of future studies of ZA in the treatment of cancers and bone cancer metastasis.
\end{abstract}

Keywords: Zoledronic acid, Anticancer effect, Osteoclast, Bone cancer metastasis, Anti-resorptive drug

\section{Background}

Osteoclasts, which are abundant in the bone tissue, are multinuclear cells derived from myeloid lineage $[1,2]$. Osteoclasts are known to initiate physiologic bone remodeling during bone growth, tooth eruption and fracture healing, and also are able to mediate bone loss in pathologic conditions, such as bone cancer metastasis [3, 4]. Therefore, inhibition of osteoclasts is a potential target for the treatment of bone cancer metastasis.

\footnotetext{
* Correspondence: 156460145@qq.com

${ }^{\dagger}$ Lianwei Wang and Dengyang Fang contributed equally to this work.

${ }^{2}$ Department of Ultrasound, Fuling Central Hospital of Chongqing City, Chongqing 408300, China

Full list of author information is available at the end of the article
}

According to the Global Cancer Statistics 2018, there would have 18.1 million new cancer cases and 9.6 million deaths from cancer worldwide in 2018 [5]. Increasing global demographic trends and epidemiologic transitions indicate an ever-increasing cancer burden over the coming decades, particularly in low- and middle-income countries, with over 20 million new cancer cases expected annually as early as 2025 [6]. The bone is the third most common site of metastasis for a wide range of solid tumors including lung, breast, prostate, colorectal, thyroid, gynecologic, and melanoma, with $70 \%$ of metastatic prostate and breast cancer patients harboring bone metastasis [7], because of the close interactions between cancer cells and the bone marrow microenvironment which facilitates the growth

(c) The Author(s). 2020 Open Access This article is licensed under a Creative Commons Attribution 4.0 International License, which permits use, sharing, adaptation, distribution and reproduction in any medium or format, as long as you give appropriate credit to the original author(s) and the source, provide a link to the Creative Commons licence, and indicate if changes were made. The images or other third party material in this article are included in the article's Creative Commons licence, unless indicated otherwise in a credit line to the material. If material is not included in the article's Creative Commons licence and your intended use is not permitted by statutory regulation or exceeds the permitted use, you will need to obtain permission directly from the copyright holder. To view a copy of this licence, visit http://creativecommons.org/licenses/by/4.0/ The Creative Commons Public Domain Dedication waiver (http://creativecommons.org/publicdomain/zero/1.0/) applies to the data made available in this article, unless otherwise stated in a credit line to the data. 
of the tumors cells in the bone by providing niche, nutrients and oxygen [8]. However, the mechanism of bone cancer metastasis is very complex, including various cytokines, growth factors and other molecules involved, leading to activation of different pathways of bone resorption [9].

Zoledronic acid (ZA, C5H10N2O7P2), also called zoledronate, is the third generation of bisphosphonate (BP) with a history of only 25 years, belonging to nitrogencontaining bisphosphonate (N-BP). BP is a kind of antiresorptive drug, and has been used clinically for near 50 years [10], which is stable pyrophosphate analogues, where a carbon atom replaces the central oxygen atom, making the P-C-P backbone non-hydrolysable [11]. Furthermore, the P-C-P backbone structure allows the BP binding to hydroxyapatite in bone tissue through the chelation of $\mathrm{Ca}^{2+}[12,13]$, this is the reason why BP has high affinity with bone. Once internalized by boneresorbing osteoclasts [14], BP affects multiple pathways to lead to effective anti-resorptive activity and induces cell apoptosis $[15,16]$. ZA is the most widely used BP for its potent anti-resorptive activity, in addition, it inhibits the differentiation and apoptosis of osteoclasts [17-19]. It also has anticancer effects [15, 20], including suppressing metastasis of cancer [21, 22], inhibiting the angiogenesis [23], and the synergistic effect with other anticancer drugs $[17,20,24]$. Here, we want to elaborate the mechanisms of ZA in inhibition of differentiation and apoptosis of osteoclasts, as well as its anticancer effects, which may provide a new strategy for the treatment of cancer, especially cancer with bone metastasis.

\section{Inhibition of differentiation of osteoclasts by ZA}

An increasing body of evidence suggests that ZA inhibits the differentiation of osteoclasts in vitro through various pathways, including inhibition of receptor activator of nuclear factor $\mathrm{kB}$ ligand (RANKL)/receptor activator of nuclear factor $\kappa B$ (RANK) pathway, non-canonical Wnt/ $\mathrm{Ca}^{2+} /$ calmodulin dependent protein kinase II (CaMKII) pathway, and prevention of macrophage differentiation into osteoclasts $[19,25,26]$.

\section{Inhibition of RANKL/RANK pathway}

Osteoclasts could be regulated by RANKL, a tumor necrosis factor (TNF)-super family cytokine produced by osteocytes and stromal cells in bone tissues [27], through binding to its receptor RANK expressed on mature osteoclasts and their precursors [28]. The dysregulation of the physiological equilibrium in the RANK/RANKL pathway also leads to the pathological remodeling associated with cancer and to the development of bone metastasis [29-31].

During osteoclast formation, the RANKL is thought to bind with RANK in osteoclast precursors, and their complex recruits TNF receptor-associated factors (TRAFs), especially TRAF6, a sensitive marker of the activity of osteoclasts, which is expressed by mature osteoclasts [32]. It activates phosphatidylinositol 3-kinase (PI3K)/protein kinase B (Akt)/mTOR pathway and subsequently nuclear factor kappa B (NF- $\mathrm{kB})$ pathway [33], by promoting the phosphorylation of inhibitor of kappa $\mathrm{B} \alpha(\mathrm{I} \kappa \mathrm{B} \alpha)$ and its subsequent degradation [27], followed by increased translocation and phosphorylation of downstream p65 [34]. In addition, the RANK-TRAFs complex also activates other downstream signaling cascades, including nuclear factor of activation of $\mathrm{T}$ cells-1 (NFATc1) and c-fos, as well as multiple osteoclastogenesis-related genes, such as tartrate resistant acid phosphatase (TRAP), matrix metalloproteinases (MMP)-9 [35]. Moreover, mitogen-activated protein kinases (MAPKs), including C-Jun N-terminal kinase (JNK), extracellular signal-regulated kinase (Erk) and p38MAPK [17]. Downregulation of Erk inhibits the merging of osteoclast precursors, suppression of JNK impedes RANKL-stimulated the differentiation of osteoclasts [36], and the activation of p38MAPK contributes greatly to the early maturation of osteoclasts [37].

Many experiments have demonstrated that ZA inhibits bone destruction caused by enhanced differentiation and function of osteoclasts by interrupting RANKL/RANK pathway [17, 18, 38] (Fig. 1). ZA decreases the expression of RANK to inhibit the differentiation of osteoclasts through suppressing TNF- $\alpha$ and RANKL [39-41]. In addition, it is reported that ZA also inhibits NFATc1 and $\mathrm{c}-$ fos [17, 26, 42], suppresses NF-kB pathway through promoting the deubiquitination of TRAF6 [18], as well as the phosphorylation of tyrosine and the nuclear translocation of p65 [43].

Another receptor for RANKL has to mention is leucine-rich repeat-containing G-protein-coupled receptor 4 (LGR4, also called GPR48), which competes with RANK to bind RANKL, plays a key negative feedback mechanism in the RANK-RANKL signaling pathway that negatively regulates osteoclast differentiation and bone resorption by suppressing RANK-TRAF6 signaling and activating Goq Ca2+ induced inhibition of NFATc1 during osteoclastogenesis $[44,45]$. However, whether the relationships between ZA and LGR4 has not been found until now, and this may be a new insight of ZA against osteoclastogenesis.

\section{Inhibition of non-canonical Wnt pathway}

It is reported that non-canonical Wnt signaling, which is mainly through $\mathrm{Ca}^{2+} / \mathrm{CaMKII}$ pathway, mediates osteoclastic differentiation [39, 46, 47], and the decreased non-canonical Wnt signaling results in decreases of differentiation of osteoclasts and bone resorption [48, 49]. And once osteoclasts stimulated, their $\mathrm{Ca}^{2+}$ levels are 


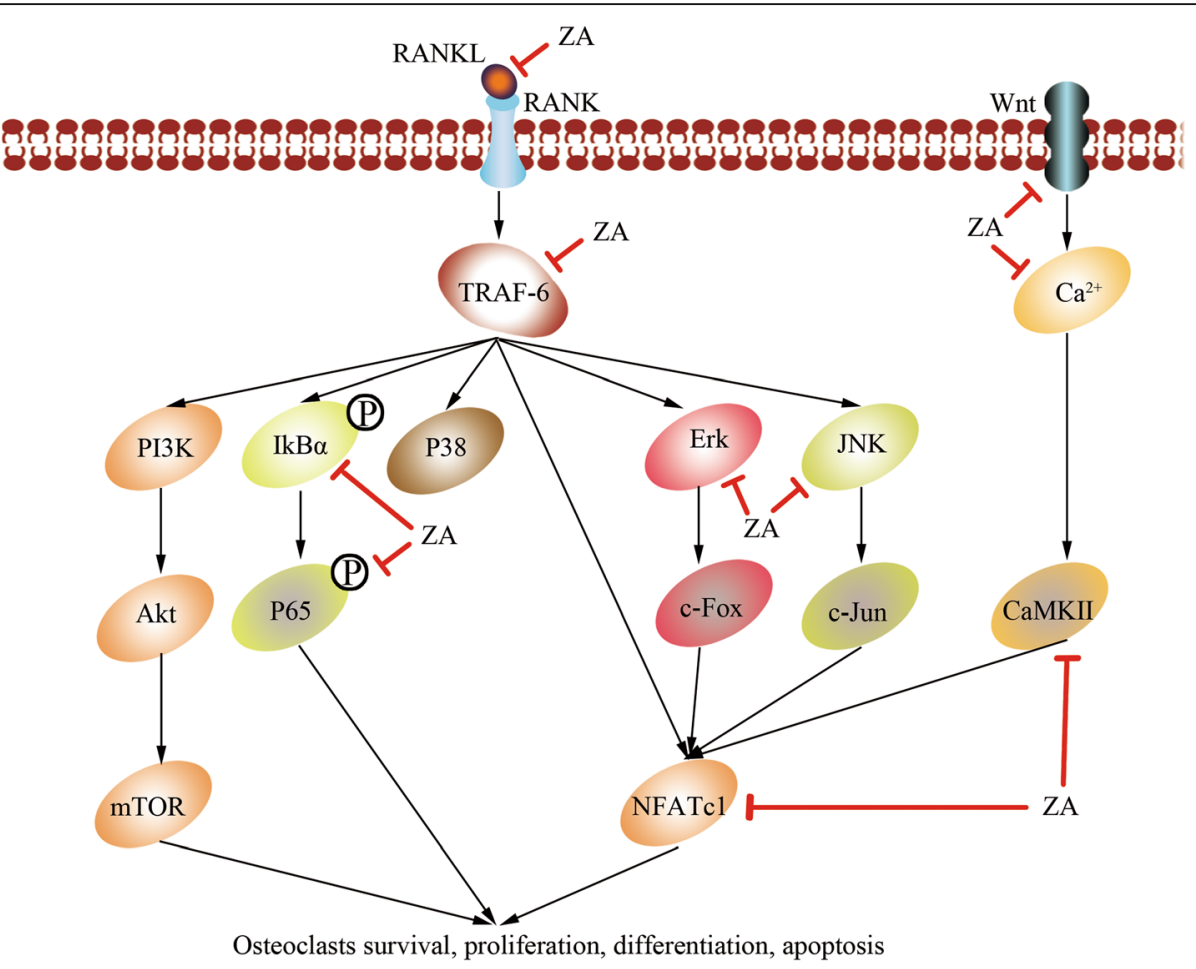

Fig. 1 ZA inhibits the RANKL/RANK pathway. The RANKL is thought to bind with RANK, and their complex recruits TNF receptor-associated factors (TRAF6), activates phosphatidylinositol 3-kinase (PI3K)/protein kinase B (Akt)/mTOR pathway and subsequently nuclear factor kappa B (NFKB) pathway, as well as nuclear factor of activation of T cells-1 (NFATc1), JNK, Erk and p38MAPK. ZA decreases the expression of RANKL to inhibit osteoclastogenesis, in addition, it is reported that ZA also inhibits NFATC1, suppresses NF-kB pathway, as well as inhibiting the phosphorylation of the nuclear translocation of p65, besides, ZA also inhibits non-canonical Wnt signaling through decreasing the signaling protein levels of Wnt5a, CaMKII, and the Ca2+ levels, and finally inhibits osteoclasts survival, proliferation, differentiation and apoptosis

upregulated, and then activates calmodulin combines with CaMKII to regulate the expression of NFATc1 and TRAP, and terminally induce osteoclastic differentiation [46, 47]. ZA inhibits non-canonical Wnt signaling through decreasing the signaling protein levels of Wnt5a and CaMKII [39]. In addition, ZA significantly decreases the $\mathrm{Ca}^{2+}$ levels, inhibits the expression of calmodulin, CaMKII [50], and its combination, finally inhibits its differentiation [39].

\section{Prevention of macrophage differentiation into osteoclasts}

As is known, Osteoclast is derived from myeloid lineage, including macrophage, monocyte, and osteoclast precursor cell $[1,2]$. In addition to RANKL in these process, macrophage colony-stimulating factor (M-CSF) is another important cytokine, produced by mesenchymal cells in the bone marrow environment. M-CSF promotes survival and proliferation of osteoclast precursors, and their differentiation into mature phagocytes, including osteoclasts [51, 52]. ZA inhibits the activity, aggregation and migration of osteoclast precursor cells and macrophage $[17,20,43,53]$ to prevent the differentiation of osteoclasts and induce apoptosis [54]. It is demonstrated that in the presence of M-CSF, ZA also inhibits RANK L-induced upregulation of RANK mRNA to suppress the differentiation of osteoclasts [41]. Nevertheless, there is not enough evidence of the relationship between ZA and M-CSF at present, which may be another potential pathway of ZA against osteoclastogenesis.

\section{Induction of apoptosis of osteoclasts}

Apoptosis literally means "falling away" in Greek, and occurs normally in multicellular organisms. It is a process to eliminate abnormal, damaged, or mutated cells, and plays important roles in embryonic development and adult tissue equilibrium by adjusting the physiological processes involved [55]. In humans, many cells are turned over and replaced each day through apoptosis. This process maintains a balance between the death and survival of cells and tissues [56]. It is demonstrated that ZA induces the apoptosis of osteoclasts through inhibition of the farnesyl pyrophosphate synthase (FPPS)-mediated mevalonate pathway, and induction of reactive oxygen species (ROS)-mediated apoptosis [24, 39, 57, 58]. 
Inhibition of the FPPS-mediated mevalonate pathway

The mevalonate pathway is an important biochemical pathway in the production of cholesterol and isoprenoids, which are essential for maintaining cell membrane integrity, producing steroids and regulating cellular respiration [59]. And isoprene precursors are crucial for the prenylation of regulatory proteins involved in the control of cell proliferation, tumor progression and cell death [59]. Therefore, inhibition of the mevalonate pathway may have an impact on cellular activities that goes beyond inhibition of bone resorption [60]. It has been revealed that ZA inhibits mevalonate pathway (Fig. 2) through inhibition of FPPS, a major regulatory enzyme, to inhibit bone resorption and induce osteoclastic apoptosis [61]. FPPS, an active dimer composed of 10 $\alpha$-helices with highly conserved sequences, is essential for the differentiation of osteoclast [62] through catalyzing the biosynthesis of geranyl pyrophosphate (GPP) and farnesyl pyrophosphate (FPP) [63]. FPP is the substrate of the geranylgeranyl pyrophosphate synthase (GGPPS) and it is converted into geranylgeranyl pyrophosphate (GGPP). The isoprene moieties from FPP and GGPP are post-translationally incorporated into several proteins, including many members of the Ras and Rho family of small GTPases, which control cell growth, proliferation, apoptosis and migration [11, 64, 65]. ZA inhibits FPPS and/or GGPPS, prevents the biosynthesis of FPP and GGPP that are required for the post-translational prenylation of small GTP-binding proteins such as Rab, Rho and Rac [66], leading to apoptosis of osteoclasts $[38,53,54,60]$.

\section{Induction of ROS-mediated apoptosis in osteoclast precursors and mature osteoclast like cells}

ROS which are deleterious at high concentrations, including superoxide anion (O2-), hydrogen peroxide [67], and also nitric oxide, cause oxidative stress in the inflammatory and apoptotic process [68]. And osteoclasts are very sensitive to oxidative stress [69]. The exposure of osteoclasts to elevate oxidative stress results in cytotoxic effects due to the increased oxidative damage of DNA, proteins, and lipids, finally leads to apoptosis via the caspase-dependent pathway [70]. Recent studies have found that ZA induces apoptosis in osteoclast precursors and mature osteoclast-like cells by increasing of NADPH oxidase subunits $\left(\mathrm{p} 91^{\text {phox }}, \mathrm{p} 22^{\text {phox }}, \mathrm{p} 47^{\text {phox }}\right.$, and p67 $\left.{ }^{\text {phox }}\right) /$ ROS to cause PI3K/AKT inactivation, glycogen synthase kinase (GSK)-3 $\beta$ activation, and the antiapoptotic protein myeloid cell leukemia 1 (Mcl-1) downregulation [71]. In addition, the increased ROS also activates JNK to induce apoptosis [72]. Moreover, the expression of pro-apoptotic protein Bax is also increased by the decreased Mcl-1, which finally leads to apoptosis through sequentially activating caspase-3 dependent apoptotic pathway [71].

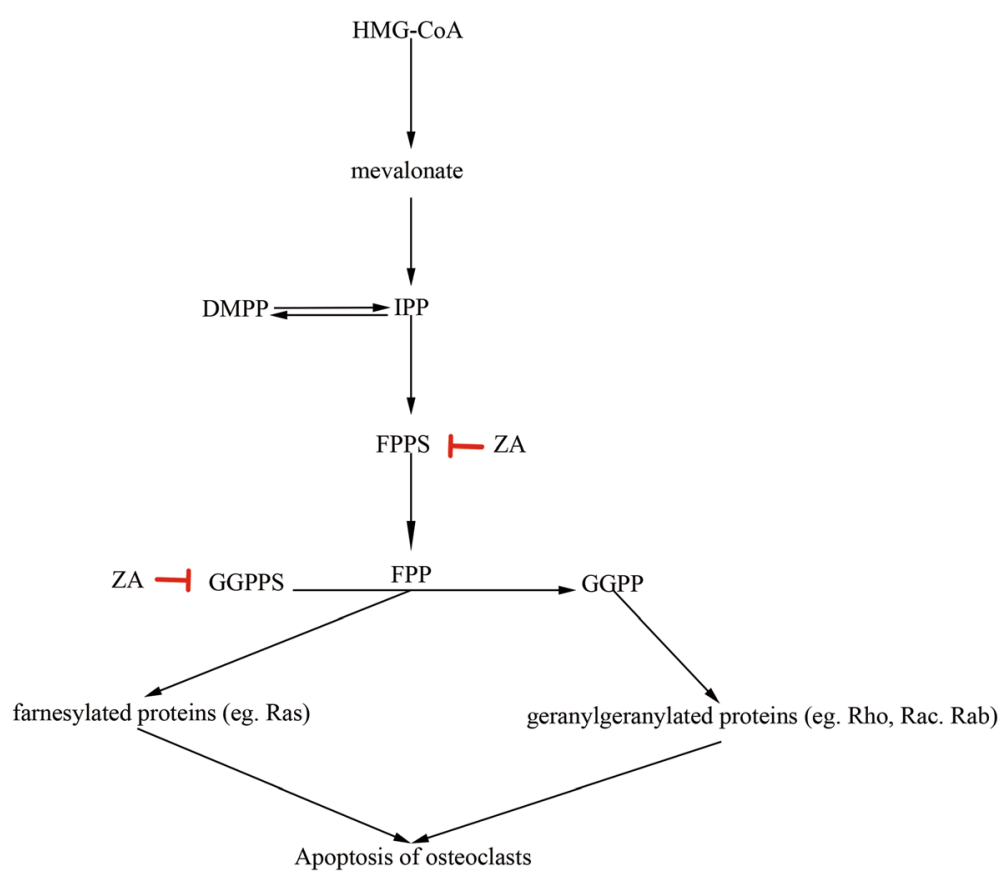

Fig. 2 ZA inhibits mevalonate pathway. ZA inhibits farnesyl pyrophosphate synthase (FPPS) and geranylgeranyl pyrophosphate synthase (GGPPS), prevents the biosynthesis of FPP and GGPP that are required for the post-translational prenylation of small GTP-binding proteins such as Rab, Rho and Rac, leading to apoptosis of the osteoclasts 


\section{Anticancer effects of ZA}

ZA has a direct effect on cancer cell through inhibiting proliferation and migration of cancer cells and induces apoptosis in vitro [73] and in vivo [74] in multiple cancer types, such as neuroblastoma [21], breast cancer cells [75], prostate cancer [20,76, 77], epidermoid cancer cells [78], pancreatic cancer [79]. Previous studies have shown that the use of ZA may significantly enhance apoptosis by elevating ROS levels in prostate carcinoma and salivary adenoid cystic carcinoma cell models [80, 81]. In addition, it is reported that ZA induces cancer cells apoptosis by inhibiting the production of RANKL in leukemia [82]. Moreover, ZA also increases the expression of pro-apoptotic protein Bax and decreases the expression of anti-apoptotic protein $\mathrm{Bcl}-2$, increases the permeability of cell membrane, and induces caspase- 3 dependent pathway, and finally induce apoptosis [43]. Furthermore, ZA also inhibits bone cancer metastasis through suppressing osteoclasts [21, 22, 41, 58, 83-85].

\section{Inducing apoptosis of cancer by ZA}

The protein Ras, one of the isoprenylation of small GTP binding protein we have mentioned above, is associated with the survival pathway in cancer cells of acitivating MAPK [86], and then the Erk1/2 [86] that mediates strong anti-apoptotic effects [87]. In addition, Ras also activates the PI3K/Akt pathway to induce survival [88], moreover, Akt is activated concomitantly or independently through Ras/Raf/Mek/ Erk1/2 signaling by growth factors $[89,90]$, and then upregulates Bcl-related proteins such as Bad and Mcl1 to protect from apoptosis [90].

It is reported that ZA inhibits Ras, blocks the Rasdependent Erk 1/2 and Akt pathways, and then reduces the phosphorylation of both $\mathrm{Bcl}-2$ and $\mathrm{Bad}$, activates the caspase-dependent apoptosis pathway to kill cancer cells [76, 78, 79, 91] (Fig. 3). Interestingly, ZA is reportedly to induce apoptosis through activating caspase- 3 pathway on epidermoid cancer cells [78] and breast cancer cells [92]. However, Tassone et al. found caspase- 9 is activated by ZA to induce apoptosis in treatment of pancreatic cancer cells, instead of caspase-3 [79]. This may be related with tissue-specific executioners of apoptosis in different cancer types, and may have the advantage of enhancing selectivity in therapeutical intervention. In addition, ZA-mediated apoptosis is associated with cytochrome $c$ release and consequent caspase- 9 activation $[79,92]$. ZA also induces actin rearrangements into cortical rings and that these events may drive the pancreatic cancer cells to the apoptotic process [79].

\section{Anti-angiogenesis of cancer by ZA}

ZA inhibits the differentiation, migration and secretion of proangiogenic factors of mesenchymal stromal cells

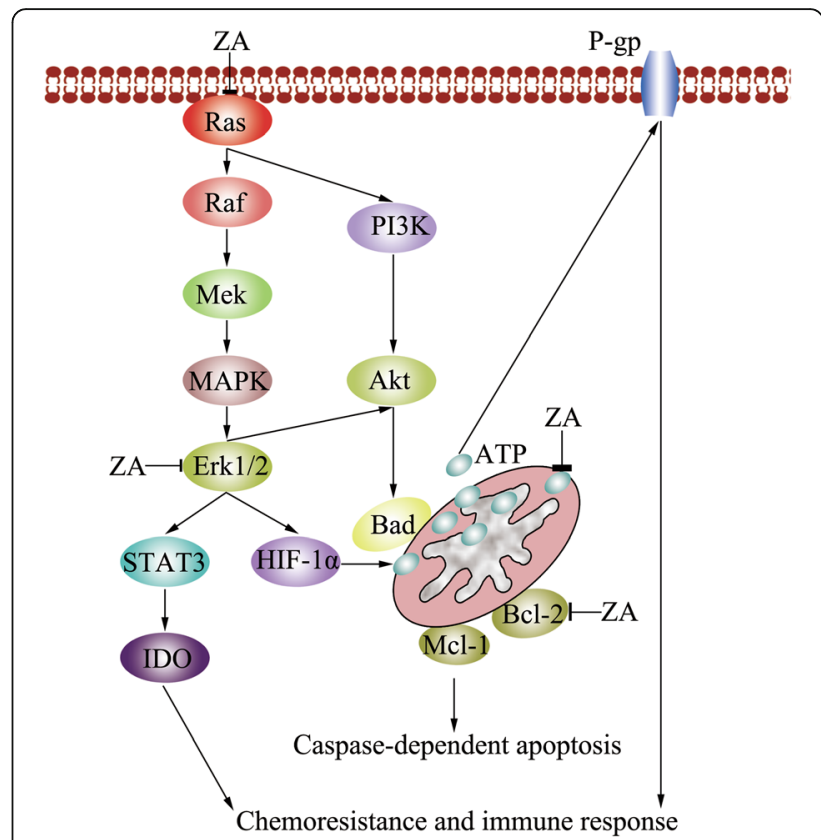

Fig. 3 ZA induces caspase-dependent apoptosis, reverts chemoresistance and stimulats immune response in cancer cells through Ras/Erk1/2 pathway. ZA inhibits Ras, blocks the Rasdependent Erk 1/2 and Akt pathways, and then reduces the phosphorylation of both Bcl-2 and Bad, activates the caspasedependent apoptosis pathway to kill cancer cells. In addition, ZA also reduces the activity of hypoxia inducible factor- 1 alpha (HIF-1a) through interrupting Ras/Erk1/2, and then suppresses the production of ATP, and decreases the drug efflux transporter Pglycoprotein (P-gp) to induce immunogenic cell death and reverses the tumor-induced immunosuppression. In addition, ZA also inhibits the signal transducer and activator of transcription-3 (STAT3)/ indoleamine 2,3 dioxygenase (IDO) axis via Ras/Erk1/2 pathway

to suppress the growth, migration and angiogenesis of prostate cancer cells [93], including vascular endothelial growth factor (VEGF) and fibroblast growth factor-2 (FGF-2), which are related to angiogenesis, immunosuppression and migration of cancer cells [94, 95]. In addition, ZA also inhibits platelet-derived growth factor$\mathrm{BB}$ (PDGF-BB), a factor released by osteoclast precursor cells could promote endothelial progenitor cells differentiating into mature endothelial cells [96], and endothelial progenitor cells to suppress angiogenesis [23].

\section{Anti-micrometastasis of cancer by ZA}

The bone marrow microenvironment provides a site for cancer cells to escape from systemic anticancer therapy, and many bone micrometastasis are believed to be formed cancer persistence and relapse [97-99]. The growth factors and cytokines released by cancer cells enter into bone marrow microenvironment, promote osteoclasts differentiation through activating RANKL/ RANK pathway with cytokines released, and finally lead to the growth and proliferation of cancer cells [100]. It is 
revealed that ZA significantly inhibits RANKL/RANK pathway to suppress micrometastasis of cancer. In addition, ZA also reduces the number and persistence of disseminated tumor cells in the bone marrow of patients with breast cancer [101, 102], through inhibiting chemokine C-C motif ligand 5 (CCL5)/chemokine receptor (CCR5) and IL-17B/17-BR [103]. CCL5/CCR5 regulates the coupling of cancer cells and mesenchymal stromal cells [104], and IL-17B/17-BR stimulates chemokines or enhancing inflammation [105], both of them facilitate the progression and metastasis of cancer cells. Moreover, ZA inhibits the expression of MMP-2 to suppress breast cancer metastasis [106]. In addition, it is reported that ZA suppresses the adhesion of cancer cells with extracellular matrix (ECM) to impair the process of invasion and metastasis [107]. Therefore, ZA may also be able to prevent distant metastases and local recurrence by decreasing the persistence of circulating tumor cells and disseminated cancer cells [60].

\section{Reverting chemoresistance and stimulating immune response by ZA}

The resistance to chemotherapy and immune escape are the main causes of the failure of treatment in cancer cells. Fortunately, it has been reported that the clinically used ZA reverses chemoresistance and immunoresisitance in vitro [108, 109] (Fig. 3). ZA interrupts Ras/ Erk1/2 downstream signaling pathways, and then reduces the activity of hypoxia inducible factor-1 alpha (HIF-1 $\alpha)$, a key element in allowing cells to adapt and survive, which increases the energy metabolism and ATP synthesis in cancer cells [110], and then, suppresses the drug efflux transporter P-glycoprotein (P-gp), decreases the glycolysis and the mitochondrial respiratory chain, and finally induce a cytochrome c/caspasedependent apoptosis in multidrug resistant cancer cells $[75,108,109,111]$. Moreover, ZA restores the doxorubicin-induced immunogenic cell death and reverses the tumor-induced immunosuppression due to the production of kynurenine, by inhibiting the signal transducer and activator of transcription-3 (STAT3)/ indoleamine 2,3 dioxygenase (IDO) axis, which is highly activated in cancer cells. These events increased the number of dendritic cells and decreased the number of immunosuppressive $\mathrm{T}$-regulatory cells infiltrating the tumors $[75,108,109]$. In addition, ZA reduces tumor burden through inhibiting FPPs, activating V $\gamma 9 \mathrm{~V} \delta 2 \mathrm{~T}$ cells, a special subsite of $\gamma \delta \mathrm{T}$ cells, to trigger activation of immunologic response through stimulating natural kill cells against cancer cells [112, 113]. ZA alters the prenylation of tumor cell and the associated macrophages to reduce tumor vascularization and prolong overall survival [114]. ZA also directly activates immunocytes of the bone marrow to kill cancer cells [115-117].

\section{Synergetic with other anticancer drugs}

ZA combines with other anticancer drugs decreases its dosage with better effects, less cytotoxic effects and side effects. The combination of metronomic ZA and coriolus versicolor inhibits the growth breast cancer without increasing lung and liver metastasis through suppressing the expression of CD34 and MMP-2 [106]. Furthermore, it is demonstrated that the treatment of ZA with other chemotherapies in children leukemia related osteonecrosis is safe and tolerant [118]. Combination therapy with ZA and tumor-specific replicating oncolytic adenovirus DBP-301 significantly inhibits tumor-mediated osteoclast activation, tumor growth and bone destruction via suppression of Mcl-1 [24]. In addition, ZA and R115777 (Zarnestra) are synergistic in inducing both growth inhibition and apoptosis in cancer cells by disruption of Ras-dependent Erk and Akt survival pathways and consequent Bcl-related proteins-dependent apoptosis [76, 78]. Meanwhile, the bi-weekly combination of Taxotere $(50 \mathrm{mg} / \mathrm{m} 2)$ followed by ZA is feasible and shows promising antitumor activity through suppressing angiogenesis, tumorigenicity and metastasis in castration resistant prostate cancer patients [77].

\section{New ways of delivering ZA against cancer}

Despite the significant antiproliferative activity of ZA on different cell lines, it has a very short plasma half-life and treads to accumulate in the bone [119]. Therefore, it is necessary to find new ways to deliver ZA in the treatment of cancer. Fortunately, it has been shown that the use of nanovectors, including liposomes (PEGylated liposomes, polysaccharides), biodegradable polymers, inorganic nanoparticles (made by metals, metal oxides or salts), hybrid nanoparticles and nanocomposite materials, can "convert" ZA in a powerful anticancer agent [120-123]. It has been reported that ZA-containing nanoparticles (N-ZA) shows superior technological characteristics in terms of mean diameter, size distribution, and ZA encapsulation efficiency, compared to ZAencapsulating PEGylated liposomes (L-ZA). Moreover, the anti-cancer activity of N-ZA outstrips L-ZA, L-ZA outstrips free $\mathrm{ZA}$ in the treatment of nude mice xenografted with prostate cancer PC3 cells, both of the N-ZA and L-ZA are without any toxic effects [124]. In addition, Transferrin (Tf)-targeted N-ZA allowed the achievement of enhanced antitumor activity of ZA in a heterotopic model of glioblastoma through the acquisition of ability to cross the blood-brain barrier [125], simultaneously, it is also a novel type of easy-to-obtain nanoparticles for the delivery of ZA in the treatment of tumors [126]. All these results suggest that the future preclinical development of ZA-encapsulating nanoparticles is a trend in the treatment of human cancer. 


\section{Conclusions}

$\mathrm{ZA}$ is a new geminal $\mathrm{BP}$ that has a heterocyclic nitrogen-containing substituent. And it is the most widely used BP for its potent antiresorptive activity. Lots of experiments have demonstrated that ZA could inhibit the differentiation of osteoclasts through the inhibition of the RANKL/ RANK pathway and non-canonical Wnt/ $\mathrm{Ca} 2+/ \mathrm{CaMKII}$ pathway, prevention of macrophage differentiation into osteoclasts, induce of apoptosis of osteoclasts through inhibition of mevalonate pathway, and induction of ROS-mediated apoptosis. Moreover, ZA could also be used to treat cancer cells via the inhibition of the proliferation, viability, motility, invasion and angiogenesis of cancer cells, induction of apoptosis, and synergic with other anti-cancer drugs. As well, we also introduce the new ways for delivering ZA against cancer, and this may provide a new strategy to improve the effect of ZA in vivo. However, the side effects of ZA whether it leads to BP-induced osteonecrosis of the jaw and cancer metastasis are still in controversial. And the pharmacokinetics of ZA suggests that it is only in solution in cancer patients under two conditions: for an hour during the annual infusion and only locally in the bone microenvironment adjacent to active osteoclasts. Therefore, more focus on the side effects of ZA and the mechanisms of ZA in cancer patients will do a great favor to clinicians.

\section{Abbreviations}

Akt: Protein kinase B; BP: Bisphosphonate; CaMKII: Calmodulin dependent protein kinase II; CCL5: Chemokine C-C motif ligand 5; CCR5: Chemokine receptor; ECM: Extracellular matrix; Erk: Extracellular signal-regulated kinase; FGF-2: Fibroblast growth factor-2; FPP: Farnesyl pyrophosphate; FPPS: Farnesyl pyrophosphate synthase; GPP: Geranyl pyrophosphate; GGPP S: Geranylgeranyl pyrophosphate synthase; GGPP: Geranylgeranyl pyrophosphate; GSK: Glycogen synthase kinase; HIF-1a: Hypoxia inducible factor-1 alpha; IDO: Indoleamine 2,3 dioxygenase; IkBa: kappa Ba; JNK: C-Jun $\mathrm{N}$-terminal kinase; LGR4: Leucine-rich repeat-containing G-protein-coupled receptor 4; L-ZA: ZA-encapsulating PEGylated liposomes; MAPKs: Mitogenactivated protein kinases; Mcl-1: Myeloid cell leukemia 1; MMP: Matrix metalloproteinases; N-BP: Nitrogen-containing bisphosphonate; NFATC:1: Nuclear factor of activation of T cells-1; NF-kB: Nuclear factor kappa B; N-ZA: ZA-containing nanoparticles; PDGF-BB: Platelet-derived growth factor-BB; P-gp: P-Glycoprotein; PI3K: Phosphatidylinositol 3-kinase; RANK: Receptor activator of nuclear factor $\mathrm{kB}$; RANKL: Receptor activator of nuclear factor KB ligand; ROS: Oxygen species; STAT3: Signal transducer and activator of transcription-3; Tf: Transferrin; TNF: Tumor necrosis factors; TRAFs: TNF receptor-associated factors; TRAP: Tartrate resistant acid phosphatase; VEGF: Vascular endothelial growth factor; ZA: Zoledronic acid

\section{Acknowledgements}

Thanks for the guidance of Dr. Zeyao Tang, from department of pharmacology, Dalian Medical University.

\section{Authors' contributions}

LWW and DYF collected the literatures, wrote and revised the manuscript, JMX drew and updated the figures, and RLL reviewed and revised the manuscript. All authors have read and approved the final manuscript.
Availability of data and materials

Not applicable.

Ethics approval and consent to participate

Not applicable.

\section{Consent for publication}

Not applicable.

\section{Competing interests}

The authors declare that they have no competing interests.

\section{Author details}

${ }^{1}$ Department of General Surgery, Fuling Central Hospital of Chongqing City, Chongqing, China. ${ }^{2}$ Department of Ultrasound, Fuling Central Hospital of Chongqing City, Chongqing 408300, China.

Received: 26 May 2020 Accepted: 26 October 2020

Published online: 03 November 2020

\section{References}

1. Chambers TJ, Fuller K, McSheehy PM, Pringle JA. The effects of calcium regulating hormones on bone resorption by isolated human osteoclastoma cells. J Pathol. 1985;145(4):297-305.

2. Madel MB, Ibanez L, Wakkach A, de Vries TJ, Teti A, Apparailly F, et al. Immune function and diversity of osteoclasts in Normal and pathological conditions. Front Immunol. 2019;10:1408.

3. Prideaux M, Findlay DM, Atkins GJ. Osteocytes: the master cells in bone remodelling. Curr Opin Pharmacol. 2016;28:24-30.

4. Tseng HC, Kanayama K, Kaur K, Park SH, Park S, Kozlowska A, et al. Bisphosphonate-induced differential modulation of immune cell function in gingiva and bone marrow in vivo: role in osteoclast-mediated NK cell activation. Oncotarget. 2015;6(24):20002-25.

5. Bray F, Ferlay J, Soerjomataram I, Siegel RL, Torre LA, Jemal A. Global cancer statistics 2018: GLOBOCAN estimates of incidence and mortality worldwide for 36 cancers in 185 countries. CA Cancer J Clin. 2018:68(6):394-424.

6. Ferlay J, Soerjomataram I, Dikshit R, Eser S, Mathers C, Rebelo M, et al. Cancer incidence and mortality worldwide: sources, methods and major patterns in GLOBOCAN 2012. Int J Cancer. 2015;136(5):E359-86.

7. Fornetti J, Welm AL, Stewart SA. Understanding the bone in Cancer metastasis. J Bone Miner Res. 2018;33(12):2099-113.

8. Ara T, Declerck YA. Interleukin-6 in bone metastasis and cancer progression. Eur J Cancer (Oxford). 2010:46(7):1223-31.

9. Sosnoski DM, Krishnan V, Kraemer WJ, Dunn-Lewis C, Mastro AM. Changes in cytokines of the bone microenvironment during breast Cancer metastasis. Int J Breast Cancer. 2012;2012:160265.

10. Fleisch H. Bisphosphonates. Pharmacology and use in the treatment of tumour-induced hypercalcaemic and metastatic bone disease. Drugs. 1991; 42(6):919-44.

11. Drake MT, Clarke BL, Khosla S. Bisphosphonates: mechanism of action and role in clinical practice. Mayo Clin Proc. 2008:83(9):1032-45.

12. Bigi A, Boanini E. Calcium Phosphates as Delivery Systems for Bisphosphonates. J Funct Biomater. 2018;9(1):6.

13. Pazianas M, van der Geest S, Miller P. Bisphosphonates and bone quality. BoneKEy Rep. 2014;3:529.

14. Yu T, Witten PE, Huysseune A, Buettner A, To TT, Winkler C. Live imaging of osteoclast inhibition by bisphosphonates in a medaka osteoporosis model. Dis Model Mech. 2016:9(2):155-63.

15. Singh T, Kaur V, Kumar M, Kaur P, Murthy RS, Rawal RK. The critical role of bisphosphonates to target bone cancer metastasis: an overview. J Drug Target. 2015;23(1):1-15.

16. Rodan GA, Fleisch HA. Bisphosphonates: mechanisms of action. J Clin Invest 1996;97(12):2692-6.

17. Qiao H, Wang TY, Yu ZF, Han XG, Liu XQ, Wang YG, et al. Structural simulation of adenosine phosphate via plumbagin and zoledronic acid competitively targets JNK/Erk to synergistically attenuate osteoclastogenesis in a breast cancer model. Cell Death Dis. 2016;7:e2094.

18. Li X, Sun W, Li J, Wang M, Zhang H, Pei L, et al. Clomipramine causes osteoporosis by promoting osteoclastogenesis via E3 ligase itch, which is prevented by Zoledronic acid. Sci Rep. 2017;7:41358.
Funding

Not applicable. 
19. Li $P$, Yang $H$, Jia $N$, Jin $X, X u D$, Shen $Y$. Experimental study on inhibitory effect of zoledronic acid on the action style of the osteoclast. Sheng wu yi xue gong cheng xue za zhi. 2017;34(1):78-82.

20. Morii K, Aoyama Y, Nakamura S, Okushin H. Synergistic anti-tumor effects of zoledronic acid and radiotherapy against metastatic hepatocellular carcinoma. Int Med. 2015;54(20):2609-13.

21. Peng H, Sohara Y, Moats RA, Nelson MD Jr, Groshen SG, Ye W, et al. The activity of zoledronic acid on neuroblastoma bone metastasis involves inhibition of osteoclasts and tumor cell survival and proliferation. Cancer Res. 2007;67(19):9346-55.

22. Hiraga T, Williams PJ, Ueda A, Tamura D, Yoneda T. Zoledronic acid inhibits visceral metastases in the 4T1/luc mouse breast cancer model. Clin Cancer Res. 2004;10(13):4559-67.

23. Gao SY, Zheng GS, Wang L, Liang YJ, Zhang SE, Lao XM, et al. Zoledronate suppressed angiogenesis and osteogenesis by inhibiting osteoclasts formation and secretion of PDGF-BB. Plos One. 2017;12(6):e0179248.

24. Yamakawa Y, Tazawa H, Hasei J, Osaki S, Omori T, Sugiu K, et al. Role of zoledronic acid in oncolytic virotherapy: promotion of antitumor effect and prevention of bone destruction. Cancer Sci. 2017;108(9):1870-80.

25. Elsayed R, Abraham P, Awad ME, Kurago Z, Baladhandayutham B, Whitford GM, et al. Removal of matrix-bound zoledronate prevents post-extraction osteonecrosis of the jaw by rescuing osteoclast function. Bone. 2018;110:141-9.

26. Nakagawa T, Ohta K, Kubozono K, Ishida Y, Naruse T, Takechi M, et al. Zoledronate inhibits receptor activator of nuclear factor kappa-B ligandinduced osteoclast differentiation via suppression of expression of nuclear factor of activated T-cell $\mathrm{Cl}$ and carbonic anhydrase 2. Arch Oral Biol. 2015; 60(4):557-65.

27. Boyle WJ, Simonet WS, Lacey DL. Osteoclast differentiation and activation. Nature. 2003;423(6937):337-42.

28. Leibbrandt A, Penninger JM. RANK/RANKL: regulators of immune responses and bone physiology. Ann N Y Acad Sci. 2008;1143:123-50.

29. Lu Y, Cai Z, Xiao G, Keller ET, Mizokami A, Yao Z, et al. Monocyte chemotactic protein-1 mediates prostate cancer-induced bone resorption. Cancer Res. 2007;67(8):3646-53

30. Yee AJ, Raje NS. Denosumab for the treatment of bone disease in solid tumors and multiple myeloma. Future Oncol. 2018;14(3):195-203.

31. Criscitiello C, Viale G, Gelao L, Esposito A, De Laurentiis M, De Placido S, et al. Crosstalk between bone niche and immune system: osteoimmunology signaling as a potential target for cancer treatment Cancer Treat Rev. 2015;41(2):61-8.

32. Hong C, Quach A, Lin L, Olson J, Kwon T, Bezouglaia O, et al. Local vs. systemic administration of bisphosphonates in rat cleft bone graft: A comparative study. Plos One. 2018;13(1):e0190901.

33. Yen ML, Hsu PN, Liao HJ, Lee BH, Tsai HF. TRAF-6 dependent signaling pathway is essential for TNF-related apoptosis-inducing ligand (TRAIL) induces osteoclast differentiation. Plos One. 2012;7(6):e38048.

34. Soysa NS, Alles N. NF-kappaB functions in osteoclasts. Biochem Biophys Res Commun. 2009;378(1):1-5.

35. Lieben L. Bone: the concept of RANKL-independent osteoclastogenesis refuted. Nat Rev Rheumatol. 2016;12(11):623.

36. Park JH, Lee NK, Lee SY. Current understanding of RANK signaling in osteoclast differentiation and maturation. Mol Cells. 2017:40(10):706-13.

37. Lee SE, Woo KM, Kim SY, Kim HM, Kwack K, Lee ZH, et al. The phosphatidylinositol 3-kinase, p38, and extracellular signal-regulated kinase pathways are involved in osteoclast differentiation. Bone. 2002;30(1):71-7.

38. Cui P, Liu H, Sun J, Amizuka N, Sun Q, Li M. Zoledronate promotes bone formation by blocking osteocyte-osteoblast communication during bone defect healing. Histol Histopathol. 2018;33(1):89-99.

39. Zhang J, Park J, Lee JW, Kwon YD, Kim EC. Bisphosphonates hinder osteoblastic/osteoclastic differentiation in the maxillary sinus mucosaderived stem cells. Clin Oral Investig. 2018;22(5):1933-43.

40. Pan B, Farrugia AN, To LB, Findlay DM, Green J, Lynch K, et al. The nitrogencontaining bisphosphonate, zoledronic acid, influences RANKL expression in human osteoblast-like cells by activating TNF-alpha converting enzyme (TACE). J Bone Miner Res. 2004;19(1):147-54.

41. Kimachi K, Kajiya H, Nakayama S, Ikebe T, Okabe K. Zoledronic acid inhibits RANK expression and migration of osteoclast precursors during osteoclastogenesis. Naunyn Schmiedeberg's Arch Pharmacol. 2011;383(3):297-308.

42. Dong W, Qi M, Wang Y, Feng X, Liu H. Zoledronate and high glucose levels influence osteoclast differentiation and bone absorption via the AMPK pathway. Biochem Biophys Res Commun. 2018;505(4):1195-202.
43. Li M, Wang W, Zhu Y, Lu Y, Wan P, Yang K, et al. Molecular and cellular mechanisms for zoledronic acid-loaded magnesium-strontium alloys to inhibit giant cell tumors of bone. Acta Biomater. 2018;77:365-79.

44. Luo J, Yang Z, Ma Y, Yue Z, Lin H, Qu G, et al. LGR4 is a receptor for RANKL and negatively regulates osteoclast differentiation and bone resorption. Nat Med. 2016;22(5):539-46.

45. Dewulf J, Vangestel C, Verhoeven Y, van Dam P, Elvas F, Van den Wyngaert $\mathrm{T}$, et al. Bone metastases in the era of targeted treatments: insights from molecular biology. Q J Nucl Med Mol Imaging. 2019;63(2):98-111.

46. Negishi-Koga T, Takayanagi H. Ca2+-NFATc1 signaling is an essential axis of osteoclast differentiation. Immunol Rev. 2009;231(1):241-56.

47. Seales EC, Micoli KJ, McDonald JM. Calmodulin is a critical regulator of osteoclastic differentiation, function, and survival. J Cell Biochem. 2006; 97(1):45-55

48. Rossini M, Zanotti R, Orsolini G, Tripi G, Viapiana O, Idolazzi L, et al. Prevalence, pathogenesis, and treatment options for mastocytosis-related osteoporosis. Osteoporosis Int. 2016:27(8):2411-21.

49. Maeda K, Kobayashi Y, Koide M, Uehara S, Okamoto M, Ishihara A, et al. The Regulation of Bone Metabolism and Disorders by Wnt Signaling. Int J Mol Sci. 2019;20(22):5525

50. Li P, Lin JS, Zhang P, Dong W, Li JY, Qi MC. Influence of zoledronate on osteoclast differentiation and gene expression of calmodulin and calmodulin-dependent protein kinase II. Zhonghua kou qiang yi xue za zhi. 2013;48(11):694-8

51. Ross FP, Teitelbaum SL. alphavbeta3 and macrophage colony-stimulating factor: partners in osteoclast biology. Immunol Rev. 2005;208:88-105.

52. O'Connell PJ, Son YI, Giermasz A, Wang Z, Logar AJ, Thomson AW, et al. Type-1 polarized nature of mouse liver CD8alpha- and CD8alpha+ dendritic cells: tissue-dependent differences offset CD8alpha-related dendritic cell heterogeneity. Eur J Immunol. 2003;33(7):2007-13.

53. Shibuya I, Takami M, Miyamoto A, Karakawa A, Dezawa A, Nakamura S, et al. In vitro study of the effects of Denosumab on Giant cell tumor of bone: comparison with Zoledronic acid. Pathol Oncol Res. 2019;25(1):409-19.

54. Rogers MJ, Gordon S, Benford HL, Coxon FP, Luckman SP, Monkkonen J, et al. Cellular and molecular mechanisms of action of bisphosphonates. Cancer. 2000:88(12 Suppl):2961-78.

55. Fiandalo MV, Kyprianou N. Caspase control: protagonists of cancer cell apoptosis. Exp Oncol. 2012;34(3):165-75.

56. Fulda S, Debatin KM. Exploiting death receptor signaling pathways for tumor therapy. Biochim Biophys Acta. 2004;1705(1):27-41.

57. Tai TW, Su FC, Chen CY, Jou IM, Lin CF. Activation of p38 MAPK-regulated $\mathrm{BCl}$-xL signaling increases survival against zoledronic acid-induced apoptosis in osteoclast precursors. Bone. 2014;67:166-74.

58. Yang C, Davis JL, Zeng R, Vora P, Su X, Collins LI, et al. Antagonism of inhibitor of apoptosis proteins increases bone metastasis via unexpected osteoclast activation. Cancer Discov. 2013;3(2):212-23.

59. Fritz G. Targeting the mevalonate pathway for improved anticancer therapy. Curr Cancer Drug Targets. 2009;9(5):626-38.

60. Koul HK, Koul S, Meacham RB. New role for an established drug? Bisphosphonates as potential anticancer agents. Prostate Cancer Prostatic Dis. 2012;15(2):111-9.

61. Kimmel DB. Mechanism of action, pharmacokinetic and pharmacodynamic profile, and clinical applications of nitrogen-containing bisphosphonates. J Dent Res. 2007;86(11):1022-33.

62. Tarshis LC, Proteau PJ, Kellogg BA, Sacchettini JC, Poulter CD. Regulation of product chain length by isoprenyl diphosphate synthases. Proc Natl Acad Sci U S A. 1996;93(26):15018-23.

63. Hosfield DJ, Zhang Y, Dougan DR, Broun A, Tari LW, Swanson RV, et al. Structural basis for bisphosphonate-mediated inhibition of isoprenoid biosynthesis. J Biol Chem. 2004;279(10):8526-9.

64. Fisher JE, Rogers MJ, Halasy JM, Luckman SP, Hughes DE, Masarachia PJ, et al. Alendronate mechanism of action: geranylgeraniol, an intermediate in the mevalonate pathway, prevents inhibition of osteoclast formation, bone resorption, and kinase activation in vitro. Proc Natl Acad Sci U S A. 1999; 96(1):133-8.

65. Caraglia M, Budillon A, Tagliaferri P, Marra M, Abbruzzese A, Caponigro F. Isoprenylation of intracellular proteins as a new target for the therapy of human neoplasms: preclinical and clinical implications. Curr Drug Targets. 2005;6(3):301-23.

66. Van beek $E$, Lowik C, van der Pluijm G, Papapoulos S. The role of geranylgeranylation in bone resorption and its suppression by 
bisphosphonates in fetal bone explants in vitro: a clue to the mechanism of action of nitrogen-containing bisphosphonates. J Bone Miner Res 1999; 14(5):722-729.

67. Schroder K. NADPH oxidases in redox regulation of cell adhesion and migration. Antioxid Redox Signal. 2014;20(13):2043-58.

68. Davies KJ. Oxidative stress: the paradox of aerobic life. Biochem Soc Symp. 1995;61:1-31.

69. Harrison C. Bone disorders: targeting NOX4 knocks down osteoporosis. Nat Rev Drug Discov. 2013;12(12):904.

70. Sharma R, Callaway D, Vanegas D, Bendele M, Lopez-Cruzan M, Horn D, et al. Caspase-2 maintains bone homeostasis by inducing apoptosis of oxidatively-damaged osteoclasts. Plos One. 2014;9(4):e93696.

71. Wang CY, Yang TT, Chen CL, Lin WC, Lin CF. Reactive oxygen speciesregulated glycogen synthase kinase-3beta activation contributes to all-trans retinoic acid-induced apoptosis in granulocyte-differentiated HL60 cells. Biochem Pharmacol. 2014;88(1):86-94.

72. Tobiume K, Matsuzawa A, Takahashi T, Nishitoh H, Morita K, Takeda K, et al. ASK1 is required for sustained activations of JNK/p38 MAP kinases and apoptosis. EMBO Rep. 2001;2(3):222-8.

73. Clezardin P. Potential anticancer properties of bisphosphonates: insights from preclinical studies. Anti Cancer Agents Med Chem. 2012;12(2):102-13.

74. Cai G, Aitken D, Laslett LL, Pelletier JP, Martel-Pelletier J, Hill C, et al. Effect of intravenous Zoledronic acid on Tibiofemoral cartilage volume among patients with knee osteoarthritis with bone marrow lesions: a randomized clinical trial. Jama. 2020;323(15):1456-66.

75. Kopecka J, Porto S, Lusa S, Gazzano E, Salzano G, Pinzòn-Daza ML, et al. Zoledronic acid-encapsulating self-assembling nanoparticles and doxorubicin: a combinatorial approach to overcome simultaneously chemoresistance and immunoresistance in breast tumors. Oncotarget. 2016; 7(15):20753-72.

76. Caraglia M, Marra M, Leonetti C, Meo G, D'Alessandro AM, Baldi A, et al. R115777 (Zarnestra)/Zoledronic acid (Zometa) cooperation on inhibition of prostate cancer proliferation is paralleled by Erk/Akt inactivation and reduced BCl-2 and bad phosphorylation. J Cell Physiol. 2007;211(2):533-43.

77. Facchini G, Caraglia M, Morabito A, Marra M, Piccirillo MC, Bochicchio AM, et al. Metronomic administration of zoledronic acid and taxotere combination in castration resistant prostate cancer patients: phase I ZANTE trial. Cancer Biol Ther. 2010;10(6):543-8.

78. Caraglia M, D'Alessandro AM, Marra M, Giuberti G, Vitale G, Viscomi C, et al. The farnesyl transferase inhibitor R115777 (Zarnestra) synergistically enhances growth inhibition and apoptosis induced on epidermoid cancer cells by Zoledronic acid (Zometa) and Pamidronate. Oncogene. 2004;23(41):6900-13.

79. Tassone P, Tagliaferri P, Viscomi C, Palmieri C, Caraglia M, D'Alessandro A, et al. Zoledronic acid induces antiproliferative and apoptotic effects in human pancreatic cancer cells in vitro. Br J Cancer. 2003;88(12):1971-8.

80. Bruzzese F, Pucci B, Milone MR, Ciardiello C, Franco R, Chianese Ml, et al. Panobinostat synergizes with zoledronic acid in prostate cancer and multiple myeloma models by increasing ROS and modulating mevalonate and p38-MAPK pathways. Cell Death Dis. 2013:4:e878.

81. Ge XY, Yang LQ, Jiang Y, Yang WW, Fu J, Li SL. Reactive oxygen species and autophagy associated apoptosis and limitation of clonogenic survival induced by zoledronic acid in salivary adenoid cystic carcinoma cell line SACC-83. PLoS One. 2014;9(6):e101207.

82. Cheung LC, Tickner J, Hughes AM, Skut P, Howlett M, Foley B, et al. New therapeutic opportunities from dissecting the pre-B leukemia bone marrow microenvironment. Leukemia. 2018;32(11):2326-38.

83. Orita Y, Sugitani I, Toda K, Manabe J, Fujimoto Y. Zoledronic acid in the treatment of bone metastases from differentiated thyroid carcinoma. Thyroid. 2011;21(1):31-5.

84. Thudi NK, Martin CK, Nadella MV, Fernandez SA, Werbeck JL, Pinzone J J, et al. Zoledronic acid decreased osteolysis but not bone metastasis in a nude mouse model of canine prostate cancer with mixed bone lesions. Prostate. 2008;68(10):1116-25

85. Hirbe AC, Roelofs AJ, Floyd DH, Deng H, Becker SN, Lanigan LG, et al. The bisphosphonate zoledronic acid decreases tumor growth in bone in mice with defective osteoclasts. Bone. 2009:44(5):908-16.

86. Garrington TP, Johnson GL. Organization and regulation of mitogenactivated protein kinase signaling pathways. Curr Opin Cell Biol. 1999;11(2): 211-8.

87. Aikawa R, Komuro I, Yamazaki T, Zou Y, Kudoh S, Tanaka M, et al. Oxidative stress activates extracellular signal-regulated kinases through
Src and Ras in cultured cardiac myocytes of neonatal rats. J Clin Invest. 1997;100(7):1813-21.

88. von Gise A, Lorenz P, Wellbrock C, Hemmings B, Berberich-Siebelt F, Rapp UR, et al. Apoptosis suppression by Raf-1 and MEK1 requires MEK- and phosphatidylinositol 3-kinase-dependent signals. Mol Cell Biol. 2001;21(7): 2324-36.

89. Liu B, Fang M, Lu Y, Mendelsohn J, Fan Z. Fibroblast growth factor and insulin-like growth factor differentially modulate the apoptosis and G1 arrest induced by anti-epidermal growth factor receptor monoclonal antibody. Oncogene. 2001;20(15):1913-22.

90. Kuo ML, Chuang SE, Lin MT, Yang SY. The involvement of PI 3-K/Aktdependent up-regulation of $\mathrm{Mcl}-1$ in the prevention of apoptosis of Hep3B cells by interleukin-6. Oncogene. 2001;20(6):677-85.

91. Marra M, Santini D, Meo G, Vincenzi B, Zappavigna S, Baldi A, et al. Cyr61 downmodulation potentiates the anticancer effects of zoledronic acid in androgen-independent prostate cancer cells. Int J Cancer. 2009;125(9):2004-13.

92. Senaratne SG, Mansi JL, Colston KW. The bisphosphonate zoledronic acid impairs Ras membrane [correction of impairs membrane] localisation and induces cytochrome c release in breast cancer cells. Br J Cancer. 2002;86(9): 1479-86.

93. Borghese C, Casagrande N, Pivetta E, Colombatti A, Boccellino M, Amler E, et al. Self-assembling nanoparticles encapsulating zoledronic acid inhibit mesenchymal stromal cells differentiation, migration and secretion of proangiogenic factors and their interactions with prostate cancer cells. Oncotarget. 2017;8(26):42926-38.

94. Cheng J, Yang K, Zhang Q, Yu Y, Meng Q, Mo N, et al. The role of mesenchymal stem cells in promoting the transformation of androgendependent human prostate cancer cells into androgen-independent manner. Sci Rep. 2016;6:16993.

95. Bergfeld SA, Blavier L, DeClerck YA. Bone marrow-derived mesenchymal stromal cells promote survival and drug resistance in tumor cells. Mol Cancer Ther. 2014;13(4):962-75.

96. Wang $H$, Yin Y, Li W, Zhao X, Yu Y, Zhu J, et al. Over-expression of PDGFRbeta promotes PDGF-induced proliferation, migration, and angiogenesis of EPCs through PI3K Akt signaling pathway. Plos One. 2012;7(2):e30503.

97. Shiozawa Y, Havens AM, Pienta KJ, Taichman RS. The bone marrow niche: habitat to hematopoietic and mesenchymal stem cells, and unwitting host to molecular parasites. Leukemia. 2008;22(5):941-50.

98. Mundy GR. Metastasis to bone: causes, consequences and therapeutic opportunities. Nat Rev Cancer. 2002;2(8):584-93.

99. Suva LJ, Washam C, Nicholas RW, Griffin RJ. Bone metastasis: mechanisms and therapeutic opportunities. Nat Rev Endocrinol. 2011;7(4):208-18.

100. Baud'huin M, Duplomb L, Ruiz Velasco C, Fortun Y, Heymann D, Padrines M. Key roles of the OPG-RANK-RANKL system in bone oncology. Expert Rev Anticancer Ther. 2007;7(2):221-32.

101. Buijs JT, Que I, Lowik CW, Papapoulos SE, van der Pluijm G. Inhibition of bone resorption and growth of breast cancer in the bone microenvironment. Bone. 2009;44(2):380-6.

102. Rack B, Juckstock J, Genss EM, Schoberth A, Schindlbeck C, Strobl B, et al. Effect of zoledronate on persisting isolated tumour cells in patients with early breast cancer. Anticancer Res. 2010;30(5):1807-13.

103. Li JJ, Chen WL, Wang JY, Hu QW, Sun ZP, Zhang S, et al. Wenshen Zhuanggu formula effectively suppresses breast cancer bone metastases in a mouse Xenograft model. Acta Pharmacol Sin. 2017;38(10):1369-80.

104. Mi Z, Bhattacharya SD, Kim VM, Guo H, Talbot LJ, Kuo PC. Osteopontin promotes CCL5-mesenchymal stromal cell-mediated breast cancer metastasis. Carcinogenesis. 2011;32(4):477-87.

105. Wu HH, Hwang-Verslues WW, Lee WH, Huang CK, Wei PC, Chen CL, et al. Targeting IL-17B-IL-17RB signaling with an anti-IL-17RB antibody blocks pancreatic cancer metastasis by silencing multiple chemokines. J Exp Med. 2015;212(3):333-49.

106. Ko CH, Yue GG, Gao S, Luo KW, Siu WS, Shum WT, et al. Evaluation of the combined use of metronomic zoledronic acid and Coriolus versicolor in intratibial breast cancer mouse model. J Ethnopharmacol. 2017;204:77-85.

107. Boissier S, Ferreras M, Peyruchaud O, Magnetto S, Ebetino FH, Colombel M, et al. Bisphosphonates inhibit breast and prostate carcinoma cell invasion, an early event in the formation of bone metastases. Cancer Res. 2000;60(11): 2949-54.

108. Salaroglio IC, Campia I, Kopecka J, Gazzano E, Orecchia S, Ghigo D, et al. Zoledronic acid overcomes chemoresistance and immunosuppression of malignant mesothelioma. Oncotarget. 2015;6(2):1128-42. 
109. Riganti C, Castella B, Kopecka J, Campia I, Coscia M, Pescarmona G, et al. Zoledronic acid restores doxorubicin chemosensitivity and immunogenic cell death in multidrug-resistant human cancer cells. PLoS One. 2013;8(4): e60975.

110. O'Donnell JL, Joyce MR, Shannon AM, Harmey J, Geraghty J, Bouchier-Hayes D. Oncological implications of hypoxia inducible factor-1alpha (HIF-1alpha) expression. Cancer Treat Rev. 2006;32(6):407-16.

111. Kopecka J, Porto S, Lusa S, Gazzano E, Salzano G, Giordano A, et al. Selfassembling nanoparticles encapsulating zoledronic acid revert multidrug resistance in cancer cells. Oncotarget. 2015;6(31):31461-78.

112. Yuasa T, Sato K, Ashihara E, Takeuchi M, Maita S, Tsuchiya N, et al. Intravesical administration of gammadelta T cells successfully prevents the growth of bladder cancer in the murine model. Cancer Immunol Immunother. 2009;58(4):493-502.

113. Gomes AQ, Martins DS, Silva-Santos B. Targeting gammadelta T lymphocytes for cancer immunotherapy: from novel mechanistic insight to clinical application. Cancer Res. 2010;70(24):10024-7.

114. Coscia M, Quaglino E, lezzi M, Curcio C, Pantaleoni F, Riganti C, et al. Zoledronic acid repolarizes tumour-associated macrophages and inhibits mammary carcinogenesis by targeting the mevalonate pathway. I Cell Mol Med. 2010;14(12):2803-15.

115. Mariani S, Muraro M, Pantaleoni F, Fiore F, Nuschak B, Peola S, et al. Effector gammadelta T cells and tumor cells as immune targets of zoledronic acid in multiple myeloma. Leukemia. 2005;19(4):664-70.

116. He Y, Wu K, Hu Y, Sheng L, Tie R, Wang B, et al. gammadelta T cell and other immune cells crosstalk in cellular immunity. J Immunol Res. 2014; 2014:960252.

117. Abe Y, Muto M, Nieda M, Nakagawa Y, Nicol A, Kaneko T, et al. Clinical and immunological evaluation of zoledronate-activated Vgamma9gammadelta T-cell-based immunotherapy for patients with multiple myeloma. Exp Hematol. 2009;37(8):956-68.

118. Padhye B, Dalla-Pozza L, Little D, Munns C. Incidence and outcome of osteonecrosis in children and adolescents after intensive therapy for acute lymphoblastic leukemia (ALL). Cancer Med. 2016;5(5):960-7.

119. Caraglia M, Marra M, Naviglio S, Botti G, Addeo R, Abbruzzese A. Zoledronic acid: an unending tale for an antiresorptive agent. Expert Opin Pharmacother. 2010;11(1):141-54.

120. Marra M, Salzano G, Leonetti C, Tassone P, Scarsella M, Zappavigna S, et al. Nanotechnologies to use bisphosphonates as potent anticancer agents: the effects of zoledronic acid encapsulated into liposomes. Nanomed. 2011;7(6): 955-64.

121. Schiraldi C, Zappavigna S, A DA, Porto S, Gaito O, Lusa S, et al. Nanoparticles for the delivery of zoledronic acid to prostate cancer cells: a comparative analysis through time lapse video-microscopy technique. Cancer Biol Ther 2014;15(11):1524-1532.

122. Salzano G, Marra M, Porru M, Zappavigna S, Abbruzzese A, La Rotonda MI, et al. Self-assembly nanoparticles for the delivery of bisphosphonates into tumors. Int J Pharm. 2011:403(1-2):292-7.

123. Ristori S, Grillo I, Lusa S, Thamm J, Valentino G, Campani V, et al. Structural characterization of self-assembling hybrid nanoparticles for bisphosphonate delivery in tumors. Mol Pharm. 2018;15(3):1258-65.

124. Marra M, Salzano G, Leonetti C, Porru M, Franco R, Zappavigna S, et al. New self-assembly nanoparticles and stealth liposomes for the delivery of zoledronic acid: a comparative study. Biotechnol Adv. 2012;30(1):302-9.

125. Porru M, Zappavigna S, Salzano G, Luce A, Stoppacciaro A, Balestrieri ML, et al. Medical treatment of orthotopic glioblastoma with transferrinconjugated nanoparticles encapsulating zoledronic acid. Oncotarget. 2014 5(21):10446-59.

126. Salzano G, Zappavigna S, Luce A, D'Onofrio N, Balestrieri ML, Grimaldi A, et al. Transferrin-targeted nanoparticles containing Zoledronic acid as a potential tool to inhibit Glioblastoma growth. J Biomed Nanotechnol. 2016; 12(4):811-30.

\section{Publisher's Note}

Springer Nature remains neutral with regard to jurisdictional claims in published maps and institutional affiliations.

\section{Ready to submit your research? Choose BMC and benefit from:}

- fast, convenient online submission

- thorough peer review by experienced researchers in your field

- rapid publication on acceptance

- support for research data, including large and complex data types

- gold Open Access which fosters wider collaboration and increased citations

- maximum visibility for your research: over $100 \mathrm{M}$ website views per year

At BMC, research is always in progress.

Learn more biomedcentral.com/submissions 